\title{
A atuação dos movimentos de doulas em Florianópolis (SC): conflitos pelo protagonismo feminino no parto
}

\author{
Actions of the doula movements in Florianópolis, Santa \\ Catarina: conflicts for female agency in childbirth
}

\author{
Carla Klitzke Espíndola* \\ Luciana Patrícia Zucco**
}

\begin{abstract}
Resumo - Este artigo tem o objetivo de analisar a dinâmica interna do movimento de doulas em Florianópolis (SC), a partir de suas pautas políticas de promoção ao parto respeitoso e ao protagonismo feminino. A pesquisa é empírica, qualitativa e orientada pelas lentes da epistemologia feminista. Os resultados apontaram conflitos entre as doulas entrevistadas, explicitando disputas de projetos, posições políticas, compreensões sobre a doulagem e diferentes formas de ver e atender mulheres. Há doulas que defendem a doulagem como profissão, um nicho de mercado; outras, como ação transitória na política de saúde pública. Por fim, aquelas que problematizam o acesso à doulagem e a branquitude de quem atende e é atendida. A "gourmetização" do parto humanizado foi transversal às narrativas. Ademais, a pluralidade das narrativas nos levou a pensar em "movimentos de doulas", devido às pautas identificadas. Apesar dos conflitos, elas convergem na compreensão da centralidade e respeito à mulher no parto.
\end{abstract}

Palavras-Chave: movimentos de doulas; parto; saúde da mulher; feminismos; direitos reprodutivos.

\begin{abstract}
This article aims to analyze the internal dynamics of the Doula Movement in Florianópolis, Santa Catarina - Brazil, based on its political guidelines for promoting respectful childbirth and female agency. This empirical, qualitative research is guided by the lens of feminist epistemology. Results pointed out conflicts between interviewed doulas, revealing disputes over projects, political positions, understandings about doulage, and different ways of seeing and
\end{abstract}

\footnotetext{
*Possui graduação (2014) e mestrado (2018) em Serviço Social pela Universidade Federal de Santa Catarina (UFSC). Especialista em Saúde da Mulher, Criança e Adolescente (2016) através de Residência Integrada Multiprofissional em Saúde (RIMS/UFSC). É pesquisadora e integrante do Núcleo Interdisciplinar de Estudos e Pesquisas em Saúde, Sexualidades e Relações de Gênero (NUSSERGE/UFSC) desde 2014. Atualmente atua como assistente social na Prefeitura Municipal de Jaraguá do Sul/SC. E-mail: carla.klitzke@gmail.com. ORCID: https://orcid.org/0000-0001-8003-6131. ** Doutora em Ciências da Saúde pelo Programa de Pós-Graduação em Saúde da Criança e da Mulher do Instituto Fernandes Figueira da Fundação Oswaldo Cruz (FIOCRUZ). É professora Associada do Departamento de Serviço Social (DSS/UFSC), do Programa de Pós-Graduação em Serviço Social da Universidade Federal de Santa Catarina (PPGSS/CSE/UFSC) e do Programa de Pós-Graduação Interdisciplinar em Ciências Humanas (PPGICH/CFH/UFSC). Coordenadora do Núcleo de Estudos em Serviço Social e Relações de Gênero (NUSSERGE/UFSC) e integrante do Instituto de Estudos de Gênero (IEG/UFSC). E-mail: Ipzucco@uol.com.br.ORCID: https://orcid.org/0000-0003-29551642.
} 
attending women. There are doulas that defend doulage as a profession, a niche market; others, as a transitory action in public health policy. Finally, there are those who problematize access to doulage, and the whiteness of those who attend and are attended. The topic of "gourmetization" of humanized childbirth was common to most narratives. In addition, the plurality of narratives led us to think in terms of "Doula Movements", due to the identified agendas. Despite

"Ser feminista é uma premissa para ser doula." (D7, doula entrevistada, 2018)

\section{Introdução}

Este trabalho é produto de uma caminhada profissional e acadêmica na área da saúde de uma das autoras, particularmente, vinculada à condição de assistente social residente no Programa de Residência Integrada Multiprofissional em Saúde (Rims), no Hospital Universitário Polydoro Ernani de São Thiago (HU) da Universidade Federal de Santa Catarina (UFSC), entre 2014 e 2016. A imersão na área da saúde da mulher e da criança proporcionou experiências multiprofissionais relacionadas ao atendimento de mulheres (gestantes, parturientes, puérperas) e de seus familiares/acompanhantes durante o período gravídico-puerperal.

Naquele espaço, emergiram diversos incômodos, dentre eles a subalternidade das mulheres grávidas ou paridas imposta pela cultura hegemônica, assim como o modo de cuidar biomédico, eurocêntrico e machista. Essas e outras inquietações decorridas da vivência profissional foram levadas à pesquisa de mestrado, e parte dos resultados stricto sensu são aqui apresentados.

Ao encontro dessas inquietudes, há um grupo de mulheres que questionam e intervêm na contramão da cultura tecnificada do parto e defendem o protagonismo das mulheres, o qual nos interessou conhecer: as doulas. Portanto, este artigo teve como objetivo analisar a dinâmica interna do movimento de doulas em Florianópolis (SC), especificamente a partir de duas pautas políticas do grupo: a promoção do parto respeitoso e o protagonismo feminino.

Partimos do pressuposto de que as doulas promovem deslocamentos dos saberes coloniais que orientam o parto e que são referendados pela racionalidade médica, assim como os reproduzem. Seus discursos são de promoção do protagonismo das mulheres-parturientes e de construção de um movimento contra-hegemônico ao saber biomédico-machista- 
conservador, que sustenta a manutenção de uma assistência obstétrica violenta no Brasil (MENDONÇA, 2015). Geram, com isso, descontinuidades na formação e no modo de assistir, mas, igualmente, reafirmam continuidades ao buscarem institucionalizar suas práticas no campo da saúde.

O referencial teórico incorporou leituras do campo interdisciplinar feminista com aproximações decoloniais. Estas possibilitaram discutir as realidades locais das doulas e problematizar a importação de modelos obstétricos europeus, bem como questionar a formação marcada pela influência norte-americana (LUGONES, 2014). A perspectiva decolonial nos oferece, igualmente, o suporte para recuperar os saberes e práticas locais, bem como a produção de conhecimento de mulheres e doulas da América Latina, muito diferente da realidade do Hemisfério Norte. Com efeito, as contribuições dos estudos feminista e de gênero, assim como da noção dos direitos sexuais e reprodutivos, promovem a descontração da "cegueira de gênero" (DINIZ, 2009), tão naturalizada na sociedade e nos modelos de atendimento obstétrico em disputa no Brasil.

Finalmente, consideramos que as reflexões e proposições aqui apresentadas são contribuições ao debate, à atuação do Serviço Social e aos estudos produzidos no âmbito da pós-graduação. As/os assistentes sociais trabalham diretamente no atendimento às mulheres e suas famílias em maternidades e diversos espaços sócio-ocupacionais, compondo as equipes de saúde. Além disso, essas/es profissionais trabalham considerando as dimensões reflexiva, crítica e socializadora de conhecimentos, em abordagens individuais e coletivas. Desse modo, o olhar atento aos saberes-poderes que atravessam o parto e o puerpério pode contribuir para intervenções críticas que privilegiam a autonomia das mulheres-parturientes, e ações que desconstruam a percepção naturalizada da submissão e o silenciamento histórico das mulheres.

Destacamos que a interlocução com as "sujeitas cognoscentes"1 da pesquisa possibilitou identificar um conjunto de dissidências e contradições entre as doulas que atuam na capital catarinense, o que nos levou a discutir os "conflitos internos" do movimento a partir dos temas que mais se projetaram durante as entrevistas. Na sequência, situamos conceitualmente as categorias orientadoras da pesquisa, o caminho percorrido para a construção dos dados e a discussão dos resultados, finalizando com as considerações.

\section{Parir no Brasil: ato de coragem}

Na conjuntura brasileira, a maioria dos partos ocorre em instituições hospitalares (TESSER et al., 2011), realidade construída por um processo

${ }^{1}$ Categoria sugerida por Salgado (2008) ao defender que todas/os sujeitas/os produzem conhecimento. 


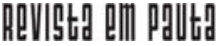

\} A ATUAÇÃO DOS MOVIMENTOS - ESPÍNDOLA, C. K.; ZUCCO, L. P. \}

DOI: $10.12957 /$ rep.2021.56079

histórico médico-científico-europeu. Esse modelo contribuiu para que os corpos das mulheres fossem demarcados pela "razão masculina", por um sistema obstétrico da desinformação (MÜLLER; RODRIGUES; PIMENTEL, 2015), pela destituição do partejar no ambiente doméstico e da participação ativa da(s) mulher(es) nesse processo (MARTINS, 2004; TORNQUIST, 2004).

Somam-se a esse contexto brasileiro os indicadores de saúde sobre parto e nascimento, que apontam que a média de cesarianas realizada no SUS por ano é de $52 \%$, e no setor privado é de $88 \%$ (TESSER et al., 2014). Essa taxa está muito acima dos 15\% recomendados pela Organização Mundial da Saúde em 2018, que considera que a cesárea representa quatro vezes mais riscos de vida à mulher-gestante e à/ao recém-nascida/o, quando comparada ao parto vaginal (CARNEIRO, 2015; TESSER et al., 2011). Os dados indicam a razão pela qual o Brasil se torna o líder mundial em cesarianas (CAD. SAÚDE PÚBLICA, 2014).

Segundo Müller, Rodrigues e Pimentel (2015), o atendimento aos partos brasileiros se resume a dois padrões: realizado pelo SUS, em que as mulheres atendidas apresentam experiências de parto normal repletas de intervenções ou realizado pela rede suplementar, com cesarianas agendadas previamente. Diante desse panorama provável de violências obstétricas, um conjunto de mulheres tem optado por modalidades de partos "desinstitucionalizados" via partos domiciliares privados, privilégio de uma pequena parcela da população (FEYER; MONTICELLI; KNOBEL, 2013). Para as autoras citadas, um dos pilares de sustentação da realidade adversa do parto e nascimento no Brasil é o discurso biomédico. A validação e aceitação social desse modelo ocorre diante do lugar de poder-saber que a medicina edificou, sustentando suas práticas em nome da veracidade do "conhecimento científico", no qual as/os sujeitas/os deixam de seguir conselhos para obedecer a ordens dos "doutores do saber" (ROHDEN, 2001).

Contudo, contrariando o discurso biomédico, os modelos obstétricos "mais intervencionistas" não resultaram na redução da mortalidade perinatal (TESSER et al., 2014). No Brasil, a mortalidade materna está para 62 casos de morte a cada 100 mil nascimentos (VARGENS; SILVA; PROGIAN, 2017). Por isso, Simone G. Diniz (2009, p. 316) afirma que o país vive um "paradoxo perinatal" na assistência ao parto, visto que convivemos com o pior de dois mundos: "o adoecimento e a morte por falta de tecnologia apropriada, e o adoecimento e a morte por excesso de tecnologia inapropriada". Nesse cenário, os movimentos de doulas se somam à crítica ao modelo intervencionista e sistematizam práticas menos invasivas como alternativa de prevenção das violências no âmbito do parto e nascimento, bem como de promoção do protagonismo das mulheres-parturientes e de um parto respeitoso. 


\section{Doulas - sinônimo de resistência}

O termo "doula" tem origem grega e foi resgatado pela antropóloga americana Dana Raphael, estudiosa da prática do aleitamento materno (SIMAS, 2016). Era utilizado para designar as mulheres que ofereciam apoio físico e emocional, bem como suporte cognitivo às mulheres grávidas e sua família em casa após o parto, auxiliando no cuidado com o bebê e em seus afazeres domésticos (FONSECA; FREITAS; RIL, 2017; SIMAS, 2016; SILVA et al., 2012).

Atualmente, o sentido e as ações foram ampliados. As doulas apoiam a mulher e seus familiares/acompanhante(s) durante o período perinatal gravidez, parto e processo de amamentação -, através de acompanhamento voluntário ou contratação de serviço por mulheres que desejam receber esse suporte ou a serviço de alguma maternidade (SIMAS, 2016). O ideal do trabalho delas é o parto natural e respeitoso, centrado na mulher, com procedimentos humanizados, seja no parto vaginal ou cesariano (FLEISCHER, 2005).

$\mathrm{Na}$ cena do parto, as doulas atuam com a mulher-parturiente e seu(s)/sua(s) acompanhante(s), aplicando medidas de assistência física, conforto e proteção, promovendo amparo emocional e disponibilizando informações. As medidas de amparo físico e emocional compreendem técnicas de relaxamento, respiração, massagens, uso de bolsa térmica, orientação acerca das posições mais confortáveis durante as contrações, promoção do encorajamento e tranquilidade durante o período do trabalho de parto. A doulagem, portanto, demanda pouca tecnologia (PORTELLA, 2017) e é, a priori, exercida exclusivamente por mulheres que possuem certificação ocupacional em curso para esta finalidade.

Pesquisas apontam que a presença de doulas junto às parturientes diminui significativamente os procedimentos rotineiros e as intervenções medicamentosas desnecessárias, reduz o tempo de trabalho de parto e minimiza as possíveis dores sentidas, tornando o parto mais prazeroso para a mulher (SILVA et al., 2012; LUMLEY; AUSTIN; CREINA, 2004). Por essa razão, a doulagem passa a ser requerida por mulheres que buscam um parto respeitoso, segundo os princípios do Movimento de Humanização do Parto e Nascimento (FERREIRA JR., 2015).

No âmbito legal, em 2013, o Ministério do Trabalho incluiu a atuação das doulas na Classificação Brasileira de Ocupações (CBO) (FONSECA; FREITAS; RIL, 2017). Todavia, elas encontram dilemas no campo hospitalar por não serem reconhecidas como profissionais de saúde (SANTOS; NUNES, 2009). Por esse motivo, algumas(ns) trabalhadoras(es) dessa área e instituições possuem uma postura de resistência à presença e atuação das doulas no cenário do parto (FERREIRA JR., 2015), inclusive por desconhecerem o seu papel (SANTOS; NUNES, 2009).

Santa Catarina se destaca por ser o primeiro estado a sancionar a lei que autoriza a atuação das doulas, iniciada na cidade de Blumenau, no 


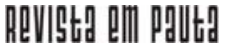

\} A ATUAÇÃO DOS MOVIMENTOS - ESPÍNDOLA, C. K.; ZUCCO, L. P. \}

DOI: $10.12957 /$ rep.2021.56079

ano de 2014, ampliando para todo estado com a Lei n. 16.869, de 15 de janeiro de 2016. Os espaços conquistados foram possíveis por força dos movimentos sociais e, posteriormente, do Estado, após a adoção da Rede Cegonha (FONSECA; FREITAS; RIL, 2017). Santa Catarina também foi pioneira ao sancionar a Lei $\mathrm{n}^{\circ} 17.097$, de 17 janeiro de 2017, que tipifica a violência obstétrica.

\section{Percurso metodológico}

Esta é uma pesquisa empírica, de abordagem qualitativa (MINAYO, 2001), orientada pela Resolução n. 466/2012 do Conselho Nacional de Saúde. Foi protocolada no Comitê de Ética em Pesquisa com Seres Humanos da UFSC (CEPSH/UFSC) e aprovada por ele em março de 2018, sob número do parecer: 2.562.762. Todas as doulas participantes da pesquisa assinaram o Termo de Consentimento Livre e Esclarecido (TCLE) e foram orientadas sobre o objetivo do estudo. As entrevistas foram semiestruturadas ${ }^{2}$ e realizadas no primeiro semestre de 2018.

Tivemos como "sujeitas cognoscentes" doulas cadastradas no HU/ UFSC e que atuam/atuaram por um período de no mínimo seis meses com a doulagem. Das 90 doulas cadastradas em um grupo online e privativo (WhatsApp) da Associação de Doulas de Santa Catarina (Adosc), nove manifestaram interesse em participar da pesquisa, sendo que cinco declinaram posteriormente aos contatos. As quatro entrevistadas responderam aos critérios de inclusão e indicaram outras cinco colegas, conforme a técnica Bola de Neve (VINUTO, 2014). Dessas, duas desistiram da pesquisa.

Durante o contato com as doulas, fomos convidadas a participar de uma reunião para debater atividades de doulagem na atenção básica no SUS, que resultou na incorporação de mais três doulas ao corpus - duas não eram associadas à Adosc. Logo, o corpus foi composto pela narrativa de dez doulas e respondeu ao critério de saturação teórica e empírica (FONTANELA et al., 2001). Entendemos, segundo Corinne Squire (2014), que as narrativas são compreendidas como práticas de processamento retrospectivo das próprias experiências de ações narradas oralmente e espontaneamente por um/a entrevistado/a.

\section{Situando as doulas entrevistadas}

As doulas entrevistadas tinham entre 28 e 40 anos, sendo que a maioria se declarou casada. Todas se autodeclararam cisgênero ${ }^{3}$. Nota-se

\footnotetext{
2 O nome das doulas será mantido em sigilo, sendo sua identificação representada pela letra " $\mathrm{D}$ " seguida de um número cardinal, que diferencia as participantes.

${ }^{3}$ Pessoas cisgenero/cissexuais saPo aquelas que encontram identificação entre seu sexo biológico e o genero socialmente designado a elas no nascimento (SOUZA; FERREIRA, 2016).
} 


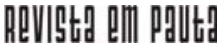

\} A ATUAÇÃO DOS MOVIMENTOS - ESPÍNDOLA, C. K.; ZUCCO, L. P. \}

DOI: $10.12957 /$ rep.2021.56079

que as regiões de procedência são diversas, mas predominaram as nascidas no Sul no Brasil; apenas uma era nascida em outro país, no Paraguai (D2).

Dentre as dez entrevistadas, um auto declarou-se negra (D9), uma parda (D7) e uma indígena (D2); as demais se consideram brancas. Segundo a narrativa de D9, ela era a única doula negra atuante em Florianópolis, o que colocou em relevo a branquitude (RIBEIRO, 2016) do segmento na capital catarinense. Referiu, ainda, não se sentir à vontade e pertencente ao Movimento do Parto Humanizado na localidade devido à cor da sua pele e origem social.

Logo, o corpus é representado por uma maioria de doulas brancas, heterossexuais, casadas, escolarizadas, residentes em centro urbano e em bairros considerados nobres, muito próximo dos resultados apresentados pela pesquisa de Raquel Simas (2016). Tais características reafirmam o clássico estereótipo das mulheres que integram o Movimento do Parto Humanizado, problematizado por Carmen S. G. Diniz (2009) e Rosamaria G. Carneiro (2015). No âmbito dos movimentos de doulas da cidade, as exclusões raciais e classistas podem reproduzir e apontar para a invisibilidade de posições e representações sobre a doulagem, colocando em xeque as pautas feministas apresentadas por esse grupo.

Quanto à escolaridade, oito doulas possuem ensino superior completo; uma doula possui mestrado. Os cursos que mais se repetiram foram psicologia (três doulas) e administração (duas doulas), logo, as áreas de conhecimento mais representativas foram ciências humanas, sociais aplicadas e saúde. Nesse aspecto, nossos dados se aproximam e corroboram com os encontrados por Antônio R. Ferreira Jr. e Barros (2016), ao constatarem a predominância do ensino superior completo e a formação em psicologia entre as entrevistadas.

A maioria fez a formação de doula a partir de 2011, somente duas realizaram antes desse período. Todas realizaram sua formação pelo Grupo de Apoio da Maternidade Ativa na cidade de São Paulo (Gama). Cinco possuem formações complementares, com referências que se distanciam da América do Norte e Europa, como cursos: "Doula na Tradição", parteiria tradicional mexicana; aromaterapia; "Core Energetic ${ }^{4 \prime}$, yoga, massoterapia holística e reiki ${ }^{5}$.

As formações complementares significam "um diferencial" no leque de qualificações das doulas, remetendo a saberes situados e as distinguindo daquelas que não possuem tais acessos. Ademais, a hierarquia curricular é "encorpada" pela quantidade de partos assistidos, alimentando o mercado de serviços do "parto gourmet". Destacamos que esta expressão

\footnotetext{
${ }^{4}$ Core energetic é um método de psicoterapia corporal que trabalha a dimensão mental, espiritual, física e emocional da pessoa, sendo essas áreas consideradas como corpos energéticos.

${ }^{5}$ Reiki é um recurso terapêutico que realiza a prática de imposição das mãos ou do toque sobre o corpo da pessoa, com a finalidade de estimular os mecanismos naturais de recuperação da saúde. Essa prática integra a Política Nacional de Práticas Integrativas e Complementares, conforme Portaria nº 849, de 27 de março de 2017, do Ministério da Saúde.
} 


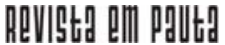

\} A ATUAÇ̃̃O DOS MOVIMENTOS - ESPÍNDOLA, C. K.; ZUCCO, L. P. \}

DOI: $10.12957 /$ rep.2021.56079

foi referenciada por D5, ao chamar a atenção para o sentido econômico e mercadológico da doulagem e do parto humanizado.

\section{"Conflitos internos" aos movimentos de doulas de Florianópolis (SC)}

Os conflitos internos aos movimentos de doulas são aqui trabalhados stricto sensu no campo da saúde, considerando as diferentes abordagens teóricas, terapêuticas e políticas. Eles explicitam as tendências e dinâmicas particulares relacionadas aos movimentos de doulas, situados em um contexto permeado por saberes e poderes. Todavia, não pretendemos cristalizar uma fronteira de demarcação como se fossem dicotomias estanques, visto que são polos fluidos e que interagem. Desse modo, nos reportamos às particularidades intrínsecas à dinâmica relacional entre as sujeitas entrevistadas, às relações próprias desse grupo, de seus saberes e às posições políticas em relação à doulagem. Foram identificados, ainda, os "conflitos externos", aqueles ligados à dinâmica conjuntural, de resistências de outras categorias profissionais e instituições às doulas; todavia, esse eixo será tratado em outra oportunidade.

Com efeito, dos "conflitos internos", marcadamente oriundos das leituras e posições diversas sobre a prática da doulagem, identificamos quatro categorias: o serviço de doulagem pago versus o voluntário; profissionalização da doulagem versus não profissionalização; defesa do mercado da humanização versus crítica à "gourmetização" do parto; "parto domiciliar privado versus parto via SUS". Destacamos, no entanto, que tais polarizações não dissipam a condição das doulas de "calcanhar de Aquiles'" do modelo biomédico tradicional ao compor os "combos das equipes "humanizadas'" no serviço privado, embora reproduzam a lógica da sociedade capitalista (BARBOSA et al., 2018, p. 427) e um modelo norte-americano de cuidado, baseado no neoliberalismo.

Quanto ao serviço de doulagem pago versus o voluntário, identificamos no campo do voluntariado de doulas duas modalidades que causam tensões e controvérsias entre a categoria: os projetos de voluntariado de doulas institucionalizados e criados por maternidades, como o caso do Hospital Sofia Feldman, e o voluntariado por iniciativa da própria doula. Aquelas doulas que se voluntariam por iniciativa própria, segundo algumas das entrevistadas, não são contrárias ao pagamento da doulagem, elas na verdade o desejam. Porém, defendem a doulagem como uma assistência às mulheres usuárias do SUS que não podem pagar pelo serviço, pois significa desembolsar um recurso médio de um salário mínimo, piso estipulado pela Adosc à época da pesquisa. Logo, a ação do voluntariado individual é contingencial entre as entrevistadas, não sendo um consenso, e evidencia 
os diferentes saberes e posições políticas que atravessam os movimentos de doulas em Florianópolis.

O desalento encontra-se na questão de considerarem seu trabalho importante e digno de receber um retorno financeiro, assim como acontece com as/os demais profissionais que assistem ao pré-natal, parto, nascimento e puerpério. Segundo Barbosa et al. (2018), há uma grande resistência das equipes de saúde em reconhecer a contribuição das doulas no cuidado à parturiente, invisibilizando essas personagens na cena do parto, sendo a questão da desvalorização financeira parte desse contexto.

Outro conflito que gera debates acalorados é a profissionalização da doulagem versus a não profissionalização. Respondendo a essa questão, está em andamento o Projeto de Lei (PL) n. 8.363/2017, que versa sobre a profissionalização das doulas, proposto pela deputada Erika Kokay, do PT/ DF. O intuito é padronizar a formação das doulas e carga-horária mínima de 180 horas, através de cursos livres, que incluam aulas teóricas e práticas supervisionadas. Até o momento da pesquisa, os cursos adotavam a carga de 32 horas, nas quais as doulas eram certificadas sem passar por estágio supervisionado obrigatório.

Nesse sentido, há aquelas que defendem a causa da profissionalização e acreditam que tal reconhecimento e organização garantiria a entrada das doulas nas maternidades públicas e privadas de todo país, além de assegurar um padrão de formação mais completo. Argumentam que a profissionalização naqueles moldes inspiraria mais respeito/confiança das/ os profissionais da saúde e instituições, bem como legitimaria um campo de trabalho formal e regulado para mulheres. Porém, a proposta de profissionalização não é apoiada por toda a categoria e associações de doulas, visto que há um discurso de que a doulagem deveria ser uma atuação transitória, por conta do atual momento de destituição das mulheres-parturientes no cenário do parto e respectivas violências obstétricas.

Para algumas entrevistadas, na medida em que se alterem as relações entre as/os sujeitas/os, a lógica institucional e a assistência ao parto e nascimento, as doulas não figurariam mais como profissionais necessárias para um parto respeitoso. Assim, para aquelas que defendem a transitoriedade da doulagem, a doula seria somente um "gatilho de acesso" a esse espaço historicamente feminino que outrora protagonizava o parto. Ademais, para algumas, o saber das doulas deveria ser incorporado por todas as mulheres e sociedade, o que, consequentemente, ajudaria a modificar a estrutura de atendimento obstétrico do país.

No entanto, em tal argumento reside um paradoxo caracterizado pela defesa da transitoriedade da doulagem versus sua remuneração, uma vez que todas as doulas que defendem o protagonismo feminino e a transitoriedade do serviço cobram pelo acompanhamento prestado. Particularmente, corroboramos com a posição de transitoriedade, pois a institucionalização dessa atuação poderia cristalizar a atual estrutura do parto e nas- 


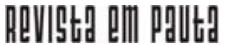

\} A ATUAÇÃO DOS MOVIMENTOS - ESPÍNDOLA, C. K.; ZUCCO, L. P. \}

DOI: $10.12957 /$ rep.2021.56079

cimento, permanecendo as mulheres-gestantes e parturientes dependentes de mais uma figura de poder-saber profissional. Ou seja, seriam dependentes de outras mulheres, em sua maioria brancas, intelectualizadas, heterossexuais e com poder econômico (SIMAS, 2016), o que não alteraria o sistema histórico de subordinação de um segmento de mulheres negras, camponesas, pobres, sem escolarização e privadas de uma série de privilégios.

Somam-se à defesa pela profissionalização da doulagem versus a não profissionalização as discussões em torno do "mercado da humanização versus crítica à 'gourmetização' do parto". No rol do mercado da humanização, Raquel Simas (2016) identificou que as doulas, durante seu curso de formação, são estimuladas a oferecer "um diferencial" às mulheres-gestantes. Isto é, outros serviços, como: fotografia; consultoria de amamentação; belly mapping (pintura da barriga da grávida para que ela reconheça o posicionamento do bebê no útero); escalda-pés; massagens etc. Segundo a autora, o parto domiciliar, considerado o "ideal de parto", também é o mais incentivado.

Com efeito, algumas doulas entrevistadas denominam esse modelo de "gourmetização" do parto humanizado, sendo contundentes em suas críticas. A noção "gourmet" ${ }^{6}$ tem o sentido de um serviço exclusivo e arrojado, um bem de consumo desejado e de difícil acesso, diríamos: elitizado. D5 sustenta que a intersecção entre raça/etnia e classe social limita o acesso ao parto humanizado, pois: "[...] tornou-se um mercado elitizado, branco, 'gourmet' [...] parece uma coisa muito, muito inatingível para uma parcela da população". Para algumas entrevistadas, o mercado "gourmet" oportuniza a venda de pacotes de serviços influenciada pela construção de um discurso em torno do parto ideal.

De modo geral, os partos "gourmet" são intermediados por um contrato, reproduzindo a lógica do capital, como indicam outros estudos (BARBOSA et al., 2018). Raquel Simas (2016) afirma que as doulas fazem contratos com as mulheres numa lógica mercadológica, assegurando o serviço por visitas ou pacotes. Constata, igualmente, que as doulas iniciantes eram orientadas a cobrar menos, por volta da metade do preço, ou não cobrar. Entretanto, o piso acordado pelo Núcleo Carioca de Doulas era entre $R \$ 1.500$ e $R \$ 5.000$, sem teto estipulado.

Soraya Fleischer $(2005$, p. 19) relata que a relação contratual, copiada do modelo estadunidense ${ }^{7}$, gera polêmicas nos movimentos de doulas, visto que algumas têm manifestado certo constrangimento em introduzir um contrato numa relação que prioriza "afeto, amor, diálogo, apoio, amizade", enquanto outras o tem utilizado. Logo, esse pacote, que envolve o protagonismo feminino, posse do corpo, respeito, afeto e relações

\footnotetext{
${ }^{6}$ No mercado comum, "gourmet" refere-se a produtos com características únicas, sofisticadas, que possuem um forte valor agregado, tendo um nicho de mercado bastante explorado por quem tem condições de o acessar.

${ }^{7} \mathrm{O}$ modelo de doulagem estadunidense absorveu valores neoliberais, tais como a valorização de relações mercadológicas, individualistas, meritocráticas, com destaque para o lucro e serviços privados (SIMAS, 2016).
} 
humanizadas no momento do parir, nascer e amamentar, é acessado mediante pagamento e por um grupo seleto. Esta associação faz sentido se comparada aos serviços do parto domiciliar, nos quais o valor mínimo cobrado em Florianópolis, em 2018, segundo a entrevistada D9, era de $\mathrm{R} \$ 10.000$.

Outro ponto de conflito nos movimentos de doulas é a discussão "parto domiciliar privado versus partos via SUS". Todas as doulas entrevistadas se mostraram preocupadas com o acesso das mulheres a um parto humanizado e respeitoso, domiciliar ou hospitalar, sendo esse um ponto comum entre elas. Todavia, as divergências aparecem diante da realidade concreta que não permite a todas as mulheres o acesso ao "parto ideal", leia-se, "parto domiciliar" (SIMAS, 2016), acentuando, com isso, as fissuras entre as doulas entrevistadas.

As doulas ligadas à defesa do SUS, que pregam a saúde como direito e não como mercadoria, revelam ser silenciadas pela Adosc, pois são a minoria do segmento catarinense e não possuem articulações políticas tão consolidadas. Apresentam muitas críticas à Adosc, por acreditarem que a associação defenda interesses particulares de um grupo privilegiado de mulheres.

Ademais, desejam que o parto domiciliar figure como política pública e direito de todas as mulheres. Inclusive, reúnem-se sistematicamente, à parte da associação, com o objetivo de planejar atividades com as Unidades Básicas de Saúde (UBS) em bairros da cidade. O conflito "parto domiciliar privado versus partos via SUS" sinaliza as tensões entre os saberes, explicitando as relações de poderes e resistência de ambos os lados, bem como os interesses de classe social envolvidos no trabalho e como eles se revelam nos movimentos de doulas.

Além das "dicotomias" identificadas nesta pesquisa, alguns estudos (FLEISCHER, 2005) apontaram outras, a saber: mulher/homem, natureza/ cultura, corporal/racional, animal/humano, prática/teoria, espiritual/terreno, sendo que a primeira categoria de cada par - "mulher", "natureza", "corpo", "animal", "prática" e "espiritual" - passa a ser positivada. Notamos que, apesar das polarizações, há uma certa fluidez entre esses pares.

\section{Considerações finais}

A abordagem dos estudos feministas e de gênero para apreensão da ação coletiva da doulagem projetou saberes produzidos por mulheres e para mulheres; saberes situados que se contrapõem aos instituídos na prestação da assistência à saúde, não sem contradições e conflitos, e que atravessam o movimento da doulagem em Florianópolis. Tais saberes explicitam opressões interseccionalizadas no campo da saúde, reproduzidas no âmbito do movimento. Cabe destacar que recorremos ao feminismo interseccional 


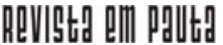

\} A ATUAÇÃO DOS MOVIMENTOS - ESPÍNDOLA, C. K.; ZUCCO, L. P. \}

DOI: $10.12957 /$ rep.2021.56079

para ampliar a compreensão dos resultados, o que nos possibilitou revelar como os diferentes marcadores sociais - raça, classe social, gênero, local de moradia - projetam opressões subliminares que atravessam a doulagem e a compreensão da assistência à mulher no momento do parto.

Os resultados explicitaram que o movimento não é monolítico, visto que revelou distintas dinâmicas em disputas, projetos contraditórios para o exercício da doulagem e conflitos em relação à pauta política do movimento. Se, por um lado, há a projeção de determinadas narrativas, que se apresentam como referências no movimento, por outro, há aquelas que atravessam as ações coletivas sem grandes projeções, mas que demarcam outros saberes sobre a assistência ao parto, embora internamente apresentem particularidades. As diferenças se encontram no processo em assistir à mulher, nos saberes mobilizados, na visão do feminino e nas demandas políticas dos segmentos que integram o movimento.

Nesse sentido, sinalizamos principalmente três dinâmicas protagonizadas pelas narrativas das entrevistadas que apontam aproximações e diferenças entre si. Há um conjunto de mulheres que compreende a doulagem como profissão a ser integrada no mercado assistencial do parto e que defende um piso salarial. A assistência é mais uma mercadoria a ser adquirida por mulheres que podem pagar, de determinada cor de pele e moradoras de áreas nobres da cidade de Florianópolis. Com efeito, a "gourmetização" do parto humanizado, com seus pacotes de serviços, catalisa divisões. Nessa ação está implícita a concepção mercadológica de saúde, que é acessível para um grupo privilegiado de mulheres.

A doulagem é, portanto, um novo nicho de mercado construído a partir da crítica à violência obstétrica. Nessa dinâmica, a pauta de luta é de reconhecimento das doulas como profissionais da saúde, que prestam um serviço pago e mobilizam, de modo geral, saberes da formação estadunidense, reportando-se, em certo sentido, à medicina baseada em evidência.

Por sua vez, há outro segmento que partilha da visão da doulagem como ação transitória no âmbito da política pública de saúde, até serem assegurados estruturalmente os princípios do parto humanizado, bem como a superação do autoritarismo e da arbitrariedade das equipes para com as mulheres parturientes. Esse grupo visa deslocamentos estruturais e atua na assistência à mulher através de ação solidária em prol de mulheres que não podem pagar pelo "parto gourmet". Tal ação nos remete às parteiras regionais, que tinham seu ofício baseado na solidariedade e confiança da comunidade.

Por fim, há um terceiro grupo de mulheres que problematiza a forma de acesso à doulagem, os aspectos relacionados à elitização do parto domiciliar e a branquitude de quem atende e de quem é atendida. O principal argumento nessa dinâmica, assim como o do segundo grupo, é a universalização e a defesa intransigente da política pública e do acesso universal. 


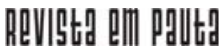

\} A ATUAÇÃO DOS MOVIMENTOS - ESPÍNDOLA, C. K.; ZUCCO, L. P. \}

DOI: $10.12957 /$ rep.2021.56079

No estudo, a "gourmetização" do parto humanizado foi hegemônica e liderada pelas integrantes e dirigentes da Adosc. As narrativas demonstraram reconhecimento de que o parto domiciliar e a doulagem atingem apenas um grupo privilegiado de mulheres; entretanto, a discussão parece ser evitada, indicando o "calcanhar de Aquiles" da associação. Desse modo, verificamos que, apesar de a Adosc ser uma instituição feminista, o recorte de classe e de raça/etnia daquelas que a dirigem acaba por influenciar suas ações e pautas.

A despeito das diferenças no âmbito do movimento, este converge para a defesa do protagonismo da mulher, a ser garantido por uma assistência respeitosa e que assegure seus direitos, aqui entendidos como sexuais e reprodutivos, capitaneados pela aproximação aos estudos feministas e, consequentemente, por uma visão ampliada do feminino. Porém, tal leitura, de certo modo, ecoa descontextualizada, uma vez que a "luta" da categoria é desprovida da incorporação dos marcadores sociais de classe, raça/etnia e gênero, e revisita o feminismo essencializado, não partilhado por todas.

Os resultados nos possibilitaram questionar se há um movimento de doulas ou movimentos de doulas, no plural, em Florianópolis, e, com isso, avançar nas contribuições asseguradas pela literatura. Essa aponta para as heterogeneidades do grupo, embora não denomine terminologicamente sua pluralidade. 


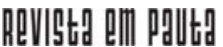

\} A ATUAÇÃO DOS MOVIMENTOS - ESPÍNDOLA, C. K.; ZUCCO, L. P. \}

DOI: $10.12957 /$ rep.2021.56079

\section{Referências}

BARBOSA, M. B. B. et al. Doulas como dispositivos para humanização do parto hospitalar: do voluntariado à mercantilização. Saúde Debate, Rio de Janeiro, v. 42, n. 117, abr./jun. 2018.

BRASIL. Ministério da Saúde. Portaria no 849, de 27 de março de 2017. Inclui a Arteterapia, Ayurveda, Biodança, Dança Circular, Meditação, Musicoterapia, Naturopatia, Osteopatia, Quiropraxia, Reflexoterapia, Reiki, Shantala, Terapia Comunitária Integrativa e Yoga à Política Nacional de Práticas Integrativas e Complementares. Diário Oficial da União., Brasília, DF, 2017.

CAD. SAÚDE PÚBLICA. Nascer no Brasil. Cad. Saúde Pública, Rio de Janeiro, v. 30, supl. 1, 2014.

CARNEIRO, R. G. Cenas de parto e políticas do corpo. Rio de Janeiro: Fiocruz, 2015.

DINIZ, C. S. G. Gênero, saúde materna e o paradoxo perinatal. Rev. Bras. Crescimento Desenvolv. Hum., v. 19, n. 2, 2009.

FERREIRA JR., A. R. Profissionalização invisível: formação e trabalho de doulas no Brasil. Tese (Doutorado em Ciências Médicas) - Universidade Estadual de Campinas, Faculdade de Ciências Médicas, Campinas, 2015.

FERREIRA JR., A. R.; BARROS, N. F. Motivos para atuação e formação profissional: percepção de doulas. Physis, v. 26, 2016.

FEYER, I. S. S.; MONTICELLI, M.; KNOBEL, R. Perfil de casais que optam por parto domiciliar assistidos por enfermeiras obstétricas. Esc. Anna Nery, v. 17, n. 2, abr./jun. 2013.

FLEISCHER, S. Doulas como "amortecedores afetivos": notas etnográficas sobre uma nova acompanhante de parto. Ciências Sociais Unisinas, v. 41, n. 1, jan./abr. 2005.

FONSECA, I.; FREITAS, R. C. M; RIL, S. Y. Movimento de doulas no Brasil: trajetória das atrizes na construção de uma cultura de não violência obstétrica. In: SEMINÁRIO INTERNACIONAL FAZENDO GÊNERO, 11, Florianópolis. Anais... Florianópolis: UFSC, 2017.

FONTANELLA, B. J. B. et al. Amostragem em pesquisas qualitativas: proposta de procedimentos para constatar saturação teórica. Cad. Saúde Pública, v. 27, n. 2, 2011.

LUGONES, M. Rumo a um feminismo descolonial. Estudos Feministas, Florianópolis, v. 22, n. 3, set./dez. 2014. 
LUMLEY, J.; AUSTIN, M. P.; CREINA, M. Intervening to reduce depression after birth: a systematic review of the randomized trials. Int. J Technol. Assess Health Care, v. 20, n. 2, 2004.

MARTINS, A. P. V. A ciência obstétrica. In: MARTINS, A. P. V. Visões do feminino: a medicina da mulher nos séculos XIX e XX. Rio de Janeiro: Editora Fiocruz, 2004.

MENDONÇA, S. S. Modelos de assistência obstétrica concorrentes e ativismo pela humanização do parto. Civitas, Porto Alegre, v. 15, n. 2, abr./jun. 2015.

MINAYO, M. C. de L. (Org.). Pesquisa social: teoria, método e criatividade. Petrópolis: Vozes, 2001.

MÜLLER, E.; RODRIGUES, L.; PIMENTEL, C. O tabu do parto. Civitas, Porto Alegre, v. 15, n. 2, abr./jun. 2015.

PORTELLA, M. de O. L. Ciência e costume na assistência ao parto. Tese (Doutorado em Sociologia) - Universidade Federal de Pernambuco, Programa de Pós-Graduação em Sociologia, Recife, 2017.

RIBEIRO, D. Feminismo negro para um novo marco civilizatório. Revista Internacional de Direitos Humanos, v. 13, n. 24, 2016.

ROHDEN, F. Uma ciência da diferença: sexo e gênero na medicina da mulher. Rio de Janeiro: Fiocruz, 2001.

SANTOS, D. S.; NUNES, I. M. Doulas na assistência ao parto: concepção de profissionais de enfermagem. Esc. Anna Nery, v. 13, n. 3, jul./set. 2009.

SALGADO, M. P. C. Metodología de la investigación feminista. México: Fundación Guatemala, 2008.

SILVA, R. M. da et al. Evidências qualitativas sobre o acompanhamento por doulas no trabalho de parto e no parto. Ciência e Saúde Coletiva, v. 17, 2012.

SIMAS, R. Doulas e o movimento pela humanização do parto Poder, gênero e a retórica do controle das emoções. Dissertação (Mestrado em Antropologia) - Universidade Federal Fluminense, Departamento de Antropologia, 2016.

SOUZA, B. C.; FERREIRA, G. G. Execução penal e população de travestis e mulheres transexuais: o caso do presídio central de Porto Alegre. Cadernos de Gênero e Diversidade, Salvador, v. 2, n. 1, jan./jul. 2016.

SQUIRE, C. O que é narrativa? Civitas, Porto Alegre, v. 14, n. 2, maio/ago. 2014.

TESSER, C. D. et al. Os médicos e o excesso de cesária no Brasil. Saúde e Transformação Social, Florianópolis, v. 2, n. 1, 2011. 


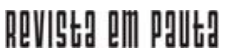

\} A ATUAÇÃO DOS MOVIMENTOS - ESPÍNDOLA, C. K.; ZUCCO, L. P. \}

DOI: $10.12957 /$ rep.2021.56079

TESSER C. D. et al. Violência obstétrica e prevenção quaternária: o que é e o que fazer. Revista Brasileira de Medicina de Família e Comunidade, Rio de Janeiro, v. 1, n. 12, 2014.

TORNQUIST, C. S. Parto e poder: o movimento pela humanização do parto no Brasil. Tese (Doutorado em Antropologia Social) - Universidade Federal de Santa Catarina, Florianópolis, 2004.

VARGENS, O. M. da C.; SILVA, A. C. V.; PROGIAN, J. M. Contribuição de enfermeiras obstétricas para consolidação do parto humanizado em maternidades no Rio de Janeiro-Brasil. Escola Anna Nery, Rio de Janeiro, v. 21, n. 1, 2017.

VINUTO, J. A amostragem em bola de neve na pesquisa qualitativa: um debate em aberto. Temáticas, Campinas, v. 22, n. 44, ago./dez. 2014.

DOI: 10.12957/rep.2021.56079

Recebido em 09 de março de 2020.

Aprovado para publicação em 19 de maio de 2020.

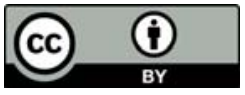

A Revista Em Pauta: Teoria Social e Realidade Contemporânea está licenciada com uma Licença Creative Commons Atribuição 4.0 Internacional. 